\section{NOTES OF A}

\section{CASE OF DIFFICULT LABOUR, DUE TO DISPLACEMENT OF THE CHUD'S ARM.}

By W. S. PLAYFAIR, M.D., M.R.C.P., Assistant Obstetric-Physician to King's College Hospital, etc.

In the first volume of his Obstetric Memoirs, Sir James Simpson has described a new, and up to that time unrecognised, "cause of obstruction in headpresentations, due to a displacement of the child's arm, which was thrown back so as to rest on the neck, inmediately below the occiput. This displacement has since been mentioned by most writers on midwifery, but I do not know of any cases in which it was met with having been placed on record. It is likely to prove a very serious obstacle to delivery for more reasons than one. One cause of difficulty is the increased bulk of the occipito-frontal circumference of the skull, which will vary according to the size of the displaced arm, but which can scarcely be under an inch more than the same diameter, when the arm is in its normal position. Another, and probably more important, element of obstruction, is the hitching of the arm on the brim of the pelvis, which may be quite sufficient to prevent the expulsion of the head at all. Of course, if the pelvis be roomy, and the head not of unusual size, it may be quite possible that the natural powers may prove sufficient to complete delivery. Indeed, Sir James Simpson mentions, in a note to his paper, that he has since seen this cause of obstruction overcome without artificial aid. In the instance presently to be related, however, it gave rise to the greatest difficulty, and eventually necessitated the performance of craniotomy; and, as the complication is rare, and likely to give rise to much embarrassment in practice, I trust it may not be useless to put on record the case that has come under my own observation.

At 6 a.m., on January 10th, 1867, I was summoned to attend Mrs. H., an out-door patient of King's College Hospital. I found that she had been in strong labour since the previous afternoon, when the membranes had ruptured. She was the mother of four children, all of whom were born alive; but her previous labours had been difficult and tedious. During the eighth month of pregnancy, she had had a severe attack of choleraic diarrhœe, which had greatly reduced her strength, a circumstance which probably accounted for the bad state in which I found her. The pains had been regular, strong, and forcing; and, the head being the presenting part, the gentleman in attendance anticipated a speedy delivery. The head progressed until it reached the floor of the pelvis, but it became arrested there, and made no further progress, although the pains continued strong and steady as before. Mr. Harding, the resident accoucheur, was sent for about midnight, and found that the head was in the third position, the anterior fontanelle being behind the left foramen ovale. By this time constitutional symptoms had arisen, calling for immediate interference. The pulse was 130, small, and feeble, the tongue was dry and black, and the comparative rapidity with which these unfavourable symptoms had shewn themselves, was doubtless owing to the previous illness of the patient. Mr. Harding applied the forceps, but failed to move the head. He then requested Dr. Fenn to see the case with him, who also made an unsuccessful attempt at delivery with the forceps. When I saw the patient, she was in a state that left no doubt as to the neces- sity of immediate intterference. I found the anterior fontanelle behind tae left foramen ovale, but on a lower level than the posterior. The margins of the orbits, and the root of the nose, were easily within reach of the finger. I, therefore, concluded that the cause of difficulty was the faulty position of the head, due to the want of flexion of the chin on the sternum. Dr. Leishman has well shown, in his work on the Mechanism of Parturition, how effectually such a malposition prevents rotation in occipito-posterior positions, and I saw no reason to doubt that it was the cause of the delay in this instance. As the forceps had already been tried, and had failed to move or rotate the head, I determined to resort to the practice so strongly recommended in similar cases by Dr. West, of Alford, and to attempt rectification of the malposition by means of the vectis. I accordingly passed it over the occiput, which I attempted to draw downwards, while upward pressure was made at the same time in front of the anterior fontanelle. The head, however, seemed firmly fixed, and no efforts that I felt justified in using had any effect in moving it. I then introduced the forceps, and met with the same want of success as my predecessors. There was no resource but craniotomy, for the patient's condition admitted of no further delay; and $I$ had the less hesitation in resorting to it, as the fotal heart was inaudible.

I accordingly perforated, anticipating that there would be no further difficulty when the brain was broken up so as to allow the skull to collapse. To my great surprise, however, the head remained as immoveable as before, nor could I succeed in drawing it down with either the craniotomy forceps or the crotchet. Passing the finger as high as possible all round, I failed to make out anything which could account for this. It was evident, therefore, that there was some obstruction higher up, which was necessarily on the part of the child, as the pelvis was of ample size, and the patient had previously given birth to living children. I next proceeded to break up the calvarium as much as possible, leaving the bones within the scalp, and then, by traction on the orbits which were easily within reach, brought down the face; as soon as I had succeeded in doing this, the head was expelled in two pains, and I found the child's arm displaced on the back of the neck in the manner described by Sir James Simpson.

It was evident that the obstruction had been caused by the arm being firmly caught on the brim of the pelvis, and lessening the head did not suffice to overcome the difficulty, because it did nothing towards dislodging the arm. As soon, however, as the face was brought down, the arm must have been pushed up by the ascent of the occiput, and the obstruction thus removed. Had the usual flexion of the head existed, I should doubtless have been able to feel the malposition of the arm; but, as it was, the faulty position of the occiput prevented the finger from reaching high enough to touch it.

When the diagnosis of such a case is made out, it would, in all probability, be sufficient to bring down the arm by the side of the head to insure natural delivery. This would, at least, prevent the possibility of the arm hitching above the brim of the pelvis; or, failing this, turning might be required, as in Sir James Simpson's case. The child in this instance was of unusual size. I had no opportunity of weighing it, but I do not think it could have been less than ten or eleven pounds. Had the child been smaller, it seems by no means impossible that the natural powers might have sufficed to overcome the obstruction; but the faulty position of the head doubtless had much influence in increasing the formidable difficulties of the case. 